\title{
Acetylation of Phenols, Anilines, and Thiols Using Silica Sulfuric Acid under Solvent-Free Conditions
}

\author{
Davood Habibi, ${ }^{1}$ Payam Rahmani, ${ }^{1}$ and Ziba Akbaripanah ${ }^{2}$ \\ ${ }^{1}$ Department of Organic Chemistry, Faculty of Chemistry, Bu-Ali Sina University, Hamedan 6517838683, Iran \\ ${ }^{2}$ Department of Central Laboratory, Jam Petrochemical Company, Assaluye-Kangan, Bushehr, \\ P.O. Box 75391-415, Iran
}

Correspondence should be addressed to Davood Habibi; davood.habibi@gmail.com

Received 1 August 2012; Revised 2 October 2012; Accepted 3 October 2012

Academic Editor: Esteban P. Urriolabeitia

Copyright (C) 2013 Davood Habibi et al. This is an open access article distributed under the Creative Commons Attribution License, which permits unrestricted use, distribution, and reproduction in any medium, provided the original work is properly cited.

Silica sulfuric acid was employed as a heterogeneous catalyst for the acetylation of a variety of phenols, amines, and thiols under solvent-free conditions at room temperature. Deactivated substrates also acetylated rapidly, and the method showed the preferential selectivity for acetylation of amino group in the presence of hydroxyl groupin which no C-acylation was observed.

\section{Introduction}

The protection of hydroxyl groups of alcohols and phenols is often necessary during the course of various transformations in a synthetic sequence, especially in the construction of polyfunctional molecules such as nucleosides, carbohydrates, steroids, and natural products. A variety of procedures are routinely performed for the preparation of acetyl derivatives, including homogeneous or heterogeneous catalysts. Protection reactions have to proceed rapidly, readily, quantitatively, and keeping costs to a minimum. Typically, the acetylation of hydroxyl groups is performed with an excess of $\mathrm{Ac}_{2} \mathrm{O}$ under basic or acidic catalysis; in some cases, acetyl halides have been used $[1,2]$.

Several methods have been developed for preparation of acetate from the corresponding phenol or thiol using various metal salts, such as $\mathrm{CoCl}_{2}$ [3], $\mathrm{ZnCl}_{2}$ [4], $\mathrm{RuCl}_{3}$ [5], $\mathrm{TiCl}_{4}$ $\mathrm{AgClO}_{4}$ [6], $\mathrm{LiClO}_{4}$ [7], $\mathrm{Mg}\left(\mathrm{ClO}_{4}\right)_{2}$ [8], $\mathrm{Zn}\left(\mathrm{ClO}_{4}\right)_{2} \cdot 6 \mathrm{H}_{2} \mathrm{O}$ [9], and some triflates such as $\mathrm{Sc}(\mathrm{OTf})_{3}$ [10], $\mathrm{Me}_{3} \mathrm{SiOTf}$ [11], In(OTf $)_{3}$ [12], $\mathrm{Cu}(\mathrm{OTf})_{2}[13,14], \mathrm{Ce}(\mathrm{OTf})_{3}$ [15], and $\mathrm{Bi}(\mathrm{OTf})_{3}$ [16]. The $\mathrm{Cp}_{2} \mathrm{Sm}(\text { thf })_{2}$ [17], tetrabutyl ammonium salt [18], and vinyl carboxylate [19] have proved to be the best catalysts for the acylation of amines with esters.

However, quite a few of the reported methods have limitations mainly in respect of stability, cost, availability, load, and reusability of the catalyst or in terms of yields and flammability or risk of explosion of the reagents. Thus, there is still a demand to develop new and mild methods for the acetylation in the presence of inexpensive and bench top reagents.

In continuation to our environmentally benign synthesis and synthesis of nitrogen-containing compounds [20-27], we intend to report a mild, clean, simple, and efficient method for the acetylation of phenols, amines, and thiols with $\mathrm{Ac}_{2} \mathrm{O}$ in the presence of silica sulfuric acid (SSA) [28] as a heterogeneous catalyst under solvent-free conditions [29-33] at room temperature (Scheme 1).

\section{Experimental}

2.1. General Procedures. All reagents were purchased from the Merck and Aldrich chemical companies and used without further purification. Products were characterized by FTIR, ${ }^{1} \mathrm{H}$ NMR, and melting points. The NMR spectra were recorded on a Bruker Avance DRX 300 and $500 \mathrm{MHz}$ instruments in DMSO and $\mathrm{CDCl}_{3}$. The chemical shifts $(\delta)$ are reported in ppm relative to the TMS as internal standard, and $J$ values are given in $\mathrm{Hz}$. FT-IR (KBr) spectra were recorded on a Perkin-Elmer 781 spectrophotometer. Melting points were taken in open capillary tubes with a BUCHI 510 melting 


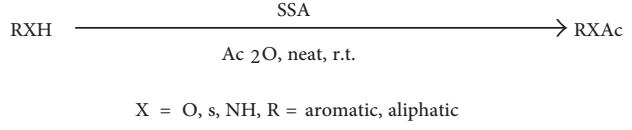

SCHEME 1: General acylation method.

TABLE 1: Solvent effect on acetylation of 4-chloroaniline by SSA at room temperature.

\begin{tabular}{lccc}
\hline Entry & Solvent & Time $(\mathrm{min})$ & Conversion (\%) \\
\hline 1 & n-Hexane & 7 & 98 \\
2 & $\mathrm{CH}_{3} \mathrm{CN}$ & 10 & 98 \\
3 & $\mathrm{CH}_{2} \mathrm{Cl}_{2}$ & 7 & 98 \\
4 & $\mathrm{CHCl}_{3}$ & 5 & 90 \\
5 & $\mathrm{MeOH}$ & 30 & 85 \\
6 & Neat & 3 & 98 \\
\hline
\end{tabular}

point apparatus and were uncorrected. TLC was performed on silica gel Polygram SIL G/UV 254 plates.

2.2. General Experimental Procedure. A mixture of substrate (phenol, amine, thiol, or thiophenol) $(1.0 \mathrm{mM}), \mathrm{Ac}_{2} \mathrm{O}$ $(2.0 \mathrm{mM})$, and SSA $(0.1 \mathrm{~g})$ was stirred at room temperature in solvent-free condition. The progress of the reaction was monitored by TLC or GC.

After completion of the reaction, $\mathrm{CH}_{2} \mathrm{Cl}_{2}$ was added, the mixture was filtered, and water $(10 \mathrm{~mL})$ was added. The mixture was extracted with $\mathrm{CH}_{2} \mathrm{Cl}_{2}(2 \times 12 \mathrm{~mL})$, and the organic layers were separated, washed with saturated $\mathrm{NaHCO}_{3}(2 \times 15 \mathrm{~mL})$ and water $(10 \mathrm{~mL})$, and dried over anhydrous $\mathrm{MgSO}_{4}$. Evaporation of the solvent followed by column chromatography on silica gel afforded the pure product.

\section{Results and Discussion}

Several experiments were carried out to optimize the amount of SSA and found that $0.1 \mathrm{~g}$ is the best condition. Reactions do not take place with less than $0.1 \mathrm{~g}$, and with more SSA, rates will remain steady.

The reaction condition was standardized after conducting the acetylation of 4-chloroaniline $(1.0 \mathrm{mM})$ with $\mathrm{Ac}_{2} \mathrm{O}$ $(2.0 \mathrm{mM})$ in the presence of SSA $(0.1 \mathrm{~g})$ using various solvents at room temperature (Table 1 ). Since the $98 \%$ yield of 4 chloroacetanilide was obtained under neat conditions, the reactions continued under solvent-free condition.

To find out the efficiency of acylating agents, 4chloroaniline was chosen as a representative electrondeficient aniline and treated with various acylating agents such as ethyl acetate, acetic acid, vinyl acetate, acetyl chloride, and $\mathrm{Ac}_{2} \mathrm{O}$ in the presence of SSA $(0.1 \mathrm{~g})$ at room temperature under solvent-free conditions (Table 2). The best result was obtained in $98 \%$ yield with $\mathrm{Ac}_{2} \mathrm{O}$, so the acetylation continued with $\mathrm{Ac}_{2} \mathrm{O}$ as a best acylating agent.

The reaction of 2-naphthol, 4-chloroaniline, and 4bromobenzenethiol $(1.0 \mathrm{mM})$ with different mole ratios of $\mathrm{Ac}_{2} \mathrm{O}(1.0,1.2,1.5,1.7$, and 2.0) was carried out in the
TABLE 2: Acylation of 4-chloroaniline (A) by different acylating reagents (B) with SSA under solvent-free conditions at room temperature.

\begin{tabular}{lcccc}
\hline Entry & Reagent & $\mathrm{A}: \mathrm{B}$ (mole ratio) & Time $(\mathrm{min})$ & Yield \% \\
\hline 1 & $\mathrm{CH}_{3} \mathrm{CO}_{2} \mathrm{Et}$ & $1.0: 2.0$ & 10 & 0 \\
2 & $\mathrm{CH}_{3} \mathrm{CO}_{2} \mathrm{H}$ & $1.0: 2.0$ & 10 & 0 \\
3 & Vinyl acetate & $1.0: 2.0$ & 10 & 20 \\
4 & $\mathrm{CH}_{3} \mathrm{COCl}$ & $1.0: 2.0$ & 10 & 95 \\
5 & $\left(\mathrm{CH}_{3} \mathrm{CO}\right)_{2} \mathrm{O}$ & $1.0: 2.0$ & 3 & 98 \\
\hline
\end{tabular}

TABLE 3: Acylation of 2-naphthol with $\mathrm{Ac}_{2} \mathrm{O}$ by SSA in solvent-free condition at room temperature.

\begin{tabular}{lcc}
\hline Entry & 2-Naphthol: $\mathrm{Ac}_{2} \mathrm{O}$ (mole ratio) & Yield \% \\
\hline 1 & $1.0: 1.0$ & 40 \\
2 & $1.0: 1.2$ & 50 \\
3 & $1.0: 1.5$ & 70 \\
4 & $1.0: 1.7$ & 83 \\
5 & $1.0: 2.0$ & 90 \\
\hline
\end{tabular}

presence of SSA $(0.1 \mathrm{~g})$ at room temperature in solvent-free condition, and the results were only reported for 2-naphthol as a representative compound (Table 3 ). The best condition was achieved with 1.0 equivalent of the substrate (2-naphthol $90 \%$, Table 4, entry 12; 4-chloroaniline $98 \%$, Table 4, entry 16; 4-bromobenzenethiol 70\%, Table 4, entry 25) and 2.0 equivalent of $\mathrm{Ac}_{2} \mathrm{O}$, so the ratio of $1: 2$ of substrate to $\mathrm{Ac}_{2} \mathrm{O}$ was used in all acylation reactions.

Then, the acylation of different types of phenols, amines, and sulfur-containing compounds was carried out with $\mathrm{Ac}_{2} \mathrm{O}$ $\left(1: 2\right.$, the mole ratio of substrate to $\left.\mathrm{Ac}_{2} \mathrm{O}\right)$ in the presence of SSA $(0.1 \mathrm{~g})$ at room temperature in solvent-free condition (Table 4$)$. All the products

The present procedure is chemoselective for the acetylation of bifunctional are known and were characterized by spectroscopic methods. compounds containing $-\mathrm{NH}_{2}$ and $-\mathrm{OH}$ groups. So, the selective acetylation of $-\mathrm{NH}_{2}$ group of ortho- or para-aminophenol was observed even with two equivalents of $\mathrm{Ac}_{2} \mathrm{O}$ to give the corresponding $o$ - or $p$-hydroxyacetanilide. This might be due to the more nucleophilicity of $-\mathrm{NH}_{2}$ group rather than $-\mathrm{OH}$ group.

Deactivated substrates could also be acetylated rapidly. For example, strongly deactivated 2-nitroaniline and 3nitroaniline (Table 4, entries 13 and 14) quantitatively afforded the corresponding acetates within 5-10 min. Again, we observed that 4-nitrophenol (Table 4, entry 9) was converted to the acetate derivatives much faster compared to the earlier reported procedure [5].

The exclusive formation of acylated products in quantitative yields is a significant achievement indicating the capability of the applied procedure.

Table 5 shows the efficiency of SSA compared with those catalysts which were used before. Most of the other catalysts either had lesser yields or needed longer reaction time for completion. 
TABLE 4: Acylation of phenols, amines, and thiols using $\mathrm{Ac}_{2} \mathrm{O}$ in the presence of SSA under solvent-free conditions at room temperature.

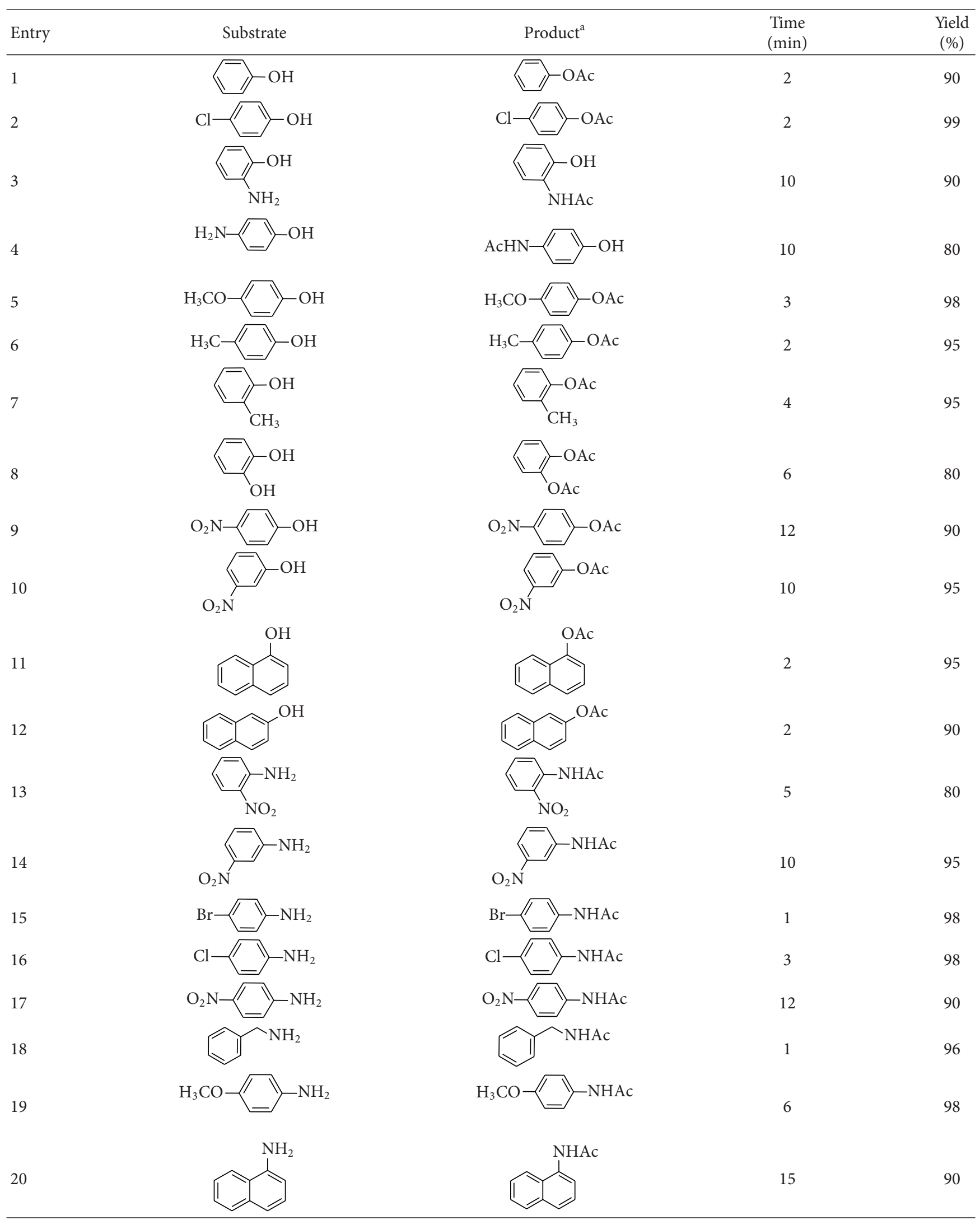


TABLE 4: Continued.

Entry Substrate

${ }^{a}$ All products were known [34-37].

TABLE 5: Comparison of different acylation methods under solvent-free conditions.

\begin{tabular}{|c|c|c|c|c|c|c|}
\hline Entry & Substrate & Reaction conditions & $\begin{array}{c}\text { Ratio } \\
\text { (substrate: acylating agent) }\end{array}$ & $\begin{array}{l}\text { Time } \\
(\min )\end{array}$ & Yield \% & $\begin{array}{c}\text { The literature } \\
\text { reference }\end{array}$ \\
\hline \multirow{4}{*}{1} & \multirow{4}{*}{ 1-Naphtol } & $\mathrm{TiCl}_{3}$ (OTf) $(1.0 \mathrm{~mol} \%), \mathrm{Ac}_{2} \mathrm{O}$, r.t. & $1.0: 2.0$ & 10 & 84 & {$[35]$} \\
\hline & & $\left(\mathrm{NH}_{4}\right)_{2.5} \mathrm{H}_{\mathrm{O} .5} \mathrm{PW}_{12} \mathrm{O}_{40}, \mathrm{Ac}_{2} \mathrm{O}$, r.t. & $1.0: 1.0$ & 2.0 & 92 & [34] \\
\hline & & $\mathrm{Zn}\left(\mathrm{ClO}_{4}\right)_{2} \cdot 6 \mathrm{H}_{2} \mathrm{O},(1.0 \mathrm{~mol} \%), \mathrm{Ac}_{2} \mathrm{O}$, r.t. & $1.0: 1.0$ & 15 & 90 & {$[36]$} \\
\hline & & SSA, $\mathrm{Ac}_{2} \mathrm{O}$, r.t. & $1.0: 2.0$ & 2.0 & 95 & Present work \\
\hline \multirow{3}{*}{2} & \multirow{3}{*}{ Benzylamine } & Sulphated zirconia, $\mathrm{Ac}_{2} \mathrm{O}$, r.t. & $1.0: 1.0$ & 10 & 85 & {$[38]$} \\
\hline & & Bromodimethylsulfonium bromide, $\mathrm{Ac}_{2} \mathrm{O}$, r.t. & $1.0: 2.0$ & 20 & 87 & {$[39]$} \\
\hline & & SSA, $\mathrm{Ac}_{2} \mathrm{O}$, r.t. & $1.0: 2.0$ & 1.0 & 96 & Present work \\
\hline \multirow{4}{*}{3} & \multirow{4}{*}{ 4-Nitrophenol } & $\mathrm{TiCl}_{3}(\mathrm{OTf})(1.0 \mathrm{~mol} \%), \mathrm{Ac}_{2} \mathrm{O}$, r.t. & $1.0: 1.0$ & 60 & 85 & {$[35]$} \\
\hline & & $\mathrm{Zn}\left(\mathrm{ClO}_{4}\right)_{2} \cdot 6 \mathrm{H}_{2} \mathrm{O},(1.0 \mathrm{~mol} \%), \mathrm{Ac}_{2} \mathrm{O}$, r.t. & $1.0: 1.0$ & 30 & 93 & [36] \\
\hline & & Bromodimethylsulfonium bromide, $\mathrm{Ac}_{2} \mathrm{O}$, r.t. & $1.0: 2.0$ & 90 & 87 & {$[39]$} \\
\hline & & SSA, $\mathrm{Ac}_{2} \mathrm{O}$, r.t. & $1.0: 2.0$ & 12 & 90 & Present work \\
\hline
\end{tabular}

3.1. Reusability of the Catalyst. We also investigated the reusability of the catalyst. For this purpose after completion of the reaction (4-chloroaniline + ethyl acetate $+\mathrm{SSA}$ ), $\mathrm{CH}_{2} \mathrm{Cl}_{2}$ was added to the reaction mixture. The catalyst was separated by a simple filtration, washed with $\mathrm{CH}_{2} \mathrm{Cl}_{2}$, and used for four successive reactions without significant loss of activity. The results of the first experiment and subsequent reactions were almost consistent in the yields.

\section{Conclusions}

We used SSA as an active and capable heterogeneous catalyst for the acylation of phenols, amines, and thiols. Moreover, this catalyst offers a mild reaction condition with short reaction times under the neat condition. Also, the present procedure is chemoselective for the $\mathrm{N}$-acetylation of bifunctional compounds containing $-\mathrm{NH}_{2}$ and $-\mathrm{OH}$ groups. In addition, deactivated substrates could also be acetylated rapidly (Table 3, entries 13 and 14).

\section{Acknowledgment}

The financial support for this work by the Bu-Ali Sina University, Hamedan, Iran is gratefully acknowledged.

\section{References}

[1] T. W. Greene and P. G. M. Wuts, Protective Groups in Organic Synthesis, John Wiley \& Sons, New York, NY, USA, 3th edition, 1999.

[2] G. Sartori, R. Ballini, F. Bigi, G. Bosica, R. Maggi, and P. Righi, "Protection (and deprotection) of functional groups in organic synthesis by heterogeneous catalysis," Chemical Reviews, vol. 104, no. 1, pp. 199-250, 2004.

[3] J. Iqbal and R. R. Srivastava, "Cobalt(II) chloride catalyzed acylation of alcohols with acetic anhydride: scope and mechanism," The Journal of Organic Chemistry, vol. 57, no. 7, pp. 2001-2007, 1992.

[4] R. H. Baker, F. G. Bordwell, C. R. Hauser et al., "Tert-Butyl acetate," Organic Syntheses, vol. 3, p. 141, 1955.

[5] S. Kanta De, "Ruthenium(III) chloride catalyzed acylation of alcohols, phenols, thiols, and amines," Tetrahedron Letters, vol. 45, no. 14, pp. 2919-2922, 2004.

[6] M. Miyashita, I. Shiina, S. Miyoshi, and T. Mukaiyama, "A new and efficient esterification reaction via mixed anhydrides by the promotion of a catalytic amount of lewis acid," Bulletin of the Chemical Society of Japan, vol. 66, no. 5, pp. 1516-1527, 1993.

[7] Y. Nakae, I. Kusaki, and T. Sato, "Lithium perchlorate catalyzed acetylation of alcohols under mild reaction conditions," Synlett, no. 10, pp. 1584-1586, 2001. 
[8] G. Bartoli, M. Bosco, R. Dalpozzo et al., " $\mathrm{Mg}\left(\mathrm{ClO}_{4}\right)_{2}$ as a powerful catalyst for the acylation of alcohols under solventfree conditions," Synlett, no. 1, pp. 39-42, 2003.

[9] G. Bartoli, M. Bosco, R. Dalpozzo, E. Marcantoni, M. Massaccesi, and L. Sambri, " $\mathrm{Zn}\left(\mathrm{ClO}_{4}\right)_{2} \cdot 6 \mathrm{H}_{2} \mathrm{O}$ as a powerful catalyst for a practical acylation of alcohols with acid anhydrides," European Journal of Organic Chemistry, vol. 2003, no. 23, pp. 4611-4617, 2003.

[10] K. Ishihara, M. Kubota, H. Kurihara, and H. Yamamoto, "Scandium trifluoromethanesulfonate as an extremely active Lewis acid catalyst in acylation of alcohols with acid anhydrides and mixed anhydrides," The Journal of Organic Chemistry, vol. 61, no. 14, pp. 4560-4567, 1996.

[11] P. A. Procopiou, S. P. D. Baugh, S. S. Flack, and G. G. A. Inglis, "An extremely powerful acylation reaction of alcohols with acid anhydrides catalyzed by trimethylsilyl trifluoromethanesulfonate," The Journal of Organic Chemistry, vol. 63, no. 7, pp. 2342-2347, 1998.

[12] K. K. Chauhan, C. G. Frost, I. Love, and D. Waite, "Indium triflate: an efficient catalyst for acylation reactions," Synlett, no. 11, pp. 1743-1744, 1999.

[13] P. Saravanan and V. K. Singh, "An efficient method for acylation reactions," Tetrahedron Letters, vol. 40, no. 13, pp. 2611-2614, 1999.

[14] K. L. Chandra, P. Saravanan, R. K. Singh, and V. K. Singh, "Lewis acid catalyzed acylation reactions: scope and limitations," Tetrahedron, vol. 58, no. 7, pp. 1369-1374, 2002.

[15] R. Dalpozzo, A. D. Nino, L. Maiuolo et al., "Highly efficient and versatile acetylation of alcohols catalyzed by cerium(III) triflate," Tetrahedron Letters, vol. 44, no. 30, pp. 5621-5624, 2003.

[16] A. Orita, C. Tanahashi, A. Kakuda, and J. Otera, "Highly efficient and versatile acylation of alcohols with $\mathrm{Bi}(\mathrm{OTf})_{3}$ as catalyst," Angewandte Chemie, vol. 39, no. 16, pp. 2877-2879, 2000.

[17] Y. Ishii, M. Takeno, Y. Kawasaki, A. Muromachi, Y. Nishiyama, and S. Sakaguchi, "Acylation of alcohols and amines with vinyl acetates catalyzed by $\mathrm{Cp} *_{2} \mathrm{Sm}(\mathrm{thf})_{2}$," The Journal of Organic Chemistry, vol. 61, no. 9, pp. 3088-3092, 1996.

[18] Y. Watanabe and T. Mukaiyama, "A convenient method for the synthesis of carboxamides and peptides by the use of tetrabutylammonium salts," Chemistry Letters, vol. 10, no. 3, pp. 285-288, 1981.

[19] S.-T. Chen, S.-Y. Chen, S.-J. Chen, and K.-T. Wang, "Vinyl carboxylate, an acylating reagent for selective acylation of amines and diols," Tetrahedron Letters, vol. 35, no. 21, pp. 3583-3584, 1994.

[20] D. Habibi and M. Nasrollahzadeh, "Silica-supported ferric chloride $\left(\mathrm{FeCl}_{3}-\mathrm{SiO}_{2}\right)$ : an efficient and recyclable heterogeneous catalyst for the preparation of arylaminotetrazoles," Synthetic Communications, vol. 40, no. 21, pp. 3159-3167, 2010.

[21] M. Nasrollahzadeh, Y. Bayat, D. Habibi, and S. Moshaee, " $\mathrm{FeCl}_{3}-\mathrm{SiO}_{2}$ as a reusable heterogeneous catalyst for the synthesis of 5-substituted $1 \mathrm{H}$-tetrazoles via [2+3] cycloaddition of nitriles and sodium azide," Tetrahedron Letters, vol. 50, no. 31, pp. 4435-4438, 2009.

[22] M. Nasrollahzadeh, D. Habibi, Z. Shahkarami, and Y. Bayat, "A general synthetic method for the formation of arylaminotetrazoles using natural natrolite zeolite as a new and reusable heterogeneous catalyst," Tetrahedron, vol. 65, no. 51, pp. 10715-10719, 2009.
[23] T. A. Kamali, D. Habibi, and M. Nasrollahzadeh, "Synthesis of 6-substituted imidazo[2,1-b][1,3]thiazoles and 2-substituted imidazo[2,1-b][1,3]benzothiazoles via $\mathrm{pd} / \mathrm{cu}$-mediated sonogashira coupling," Synlett, no. 16, pp. 2601-2604, 2009.

[24] T. A. Kamali, M. Bakherad, M. Nasrollahzadeh, S. Farhangi, and D. Habibi, "Synthesis of 6-substituted imidazo[2,1-b]thiazoles via $\mathrm{Pd} / \mathrm{Cu}$-mediated Sonogashira coupling in water," Tetrahedron Letters, vol. 50, no. 39, pp. 5459-5462, 2009.

[25] D. Habibi, M. Nasrollahzadeh, and T. A. Kamali, "Green synthesis of the 1-substituted $1 H$-1, 2, 3, 4-tetrazoles by application of the natrolite zeolite as a new and reusable heterogeneous catalyst," Green Chemistry, vol. 13, no. 12, pp. 3499-3504, 2011.

[26] D. Habibi, M. Nasrollahzadeh, and Y. Bayat, " $\mathrm{AlCl}_{3}$ as an effective lewis acid for the synthesis of arylaminotetrazoles," Synthetic Communications, vol. 41, no. 14, pp. 2135-2145, 2011.

[27] D. Habibi and M. Nasrollahzadeh, "Synthesis of arylaminotetrazoles by $\mathrm{ZnCl}_{2} / \mathrm{AlCl}_{3} /$ silica as an efficient heterogeneous catalyst," Monatshefte Für Chemie, vol. 143, no. 6, pp. 925-930, 2012.

[28] P. Salehi, M. A. Zolfigol, F. Shirini, and M. Baghbanzadeh, "Silica sulfuric acid and silica chloride as efficient reagents for organic reactions," Current Organic Chemistry, vol. 10, no. 17, pp. 2171-2189, 2006.

[29] F. Shirini, M. A. Zolfigol, and K. Mohammadi, "Silica sulfuric acid as a mild and efficient reagent for the acetylation of alcohols in solution and under solvent free conditions," Bulletin of the Korean Chemical Society, vol. 25, no. 2, pp. 325-327, 2004.

[30] F. Shirini, M. A. Zolfigol, and K. Mohammadi, "Acetylation and formylation of alcohols in the presence of silica sulfuric acid," Phosphorus, Sulfur and Silicon and the Related Elements, vol. 178, no. 7, pp. 1617-1621, 2003.

[31] H. Wu, Y. Shen, L.-Y. Fan, Y. Wan, and D.-Q. Shi, "Solid silica sulfuric acid (SSA) as a novel and efficient catalyst for acetylation of aldehydes and sugars," Tetrahedron, vol. 62, no. 34, pp. 7995-7998, 2006.

[32] H. Wu, Y. Shen, L.-Y. Fan, Y. Wan, and D.-Q. Shi, "Solid silica sulfuric acid (SSA)-catalyzed acetylation of aldehydes and sugars," Synfacts, no. 11, pp. 1187-1187, 2006.

[33] M. A. Bigdeli, N. Nahid, and M. M. Heravi, "Sulphuric acid adsorbed on silica gel. A remarkable acetylation catalyst," Iranian Journal of Chemistry and Chemical Engineering, vol. 19, no. 1, pp. 37-39, 2000.

[34] J. R. Satam and R. V. Jayaram, "Acetylation of alcohols, phenols and amines using ammonium salt of 12-tungstophosphoric acid: environmentally benign method," Catalysis Communications, vol. 9, no. 14, pp. 2365-2370, 2008.

[35] H. Firouzabadi, N. Iranpoor, and S. Farahi, "Solid trichlorotitanium(IV) trifluoromethanesulfonate $\mathrm{TiCl}_{3}$ (OTf) catalyzed efficient acylation of - $\mathrm{OH}$ and -SH: direct esterification of alcohols with carboxylic acids and transesterification of alcohols with esters under neat conditions," Journal of Molecular Catalysis A, vol. 289, no. 1-2, pp. 61-68, 2008.

[36] Shivani, R. Gulhane, and A. K. Chakraborti, "Zinc perchlorate hexahydrate $\left[\mathrm{Zn}\left(\mathrm{ClO}_{4}\right)_{2} \cdot 6 \mathrm{H}_{2} \mathrm{O}\right]$ as acylation catalyst for poor nucleophilic phenols, alcohols and amines: scope and limitations," Journal of Molecular Catalysis A, vol. 264, no. 1-2, pp. 208-213, 2007.

[37] B. Sreedhar, V. Bhaskar, C. Sridhar, T. Srinivas, L. Kótai, and K. Szentmihályi, "Acylation of alcohols and amines with carboxylic acids: a first report catalyzed by iron(III) oxidecontaining activated carbon," Journal of Molecular Catalysis A, vol. 191, no. 1, pp. 141-147, 2003. 
[38] K. J. Ratnam, R. S. Reddy, N. S. Sekhar, M. L. Kantam, and F. Figueras, "Sulphated zirconia catalyzed acylation of phenols, alcohols and amines under solvent free conditions," Journal of Molecular Catalysis A, vol. 276, no. 1-2, pp. 230-234, 2007.

[39] A. T. Khan, S. Islam, A. Majee, T. Chattopadhyay, and S. Ghosh, "Bromodimethylsulfonium bromide: a useful reagent for acylation of alcohols, phenols, amines, thiols, thiophenols and 1,1-diacylation of aldehydes under solvent free conditions," Journal of Molecular Catalysis A, vol. 239, no. 1-2, pp. 158-165, 2005. 

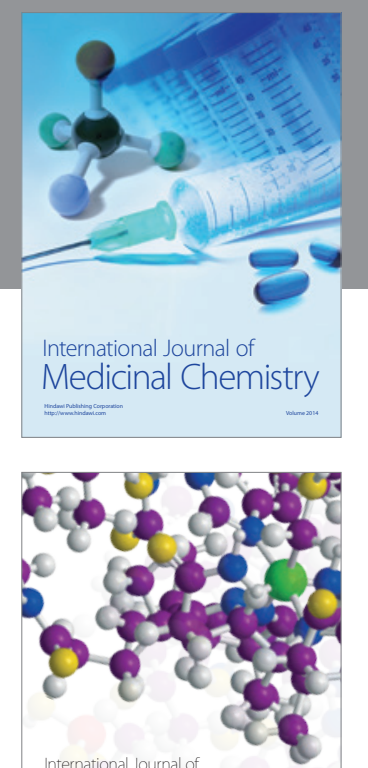

\section{Carbohydrate} Chemistry

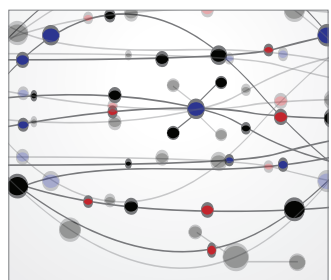

The Scientific World Journal
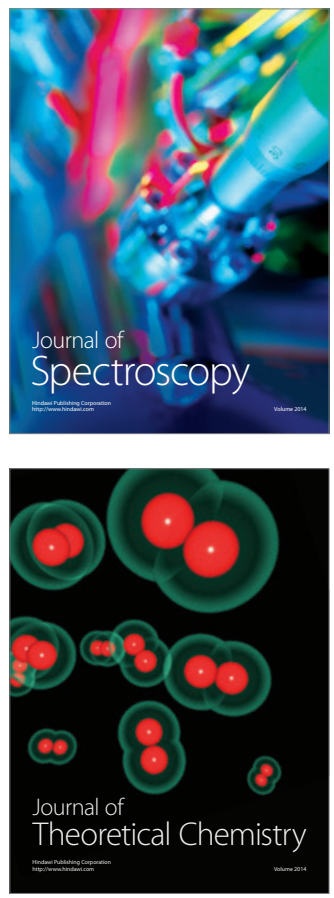
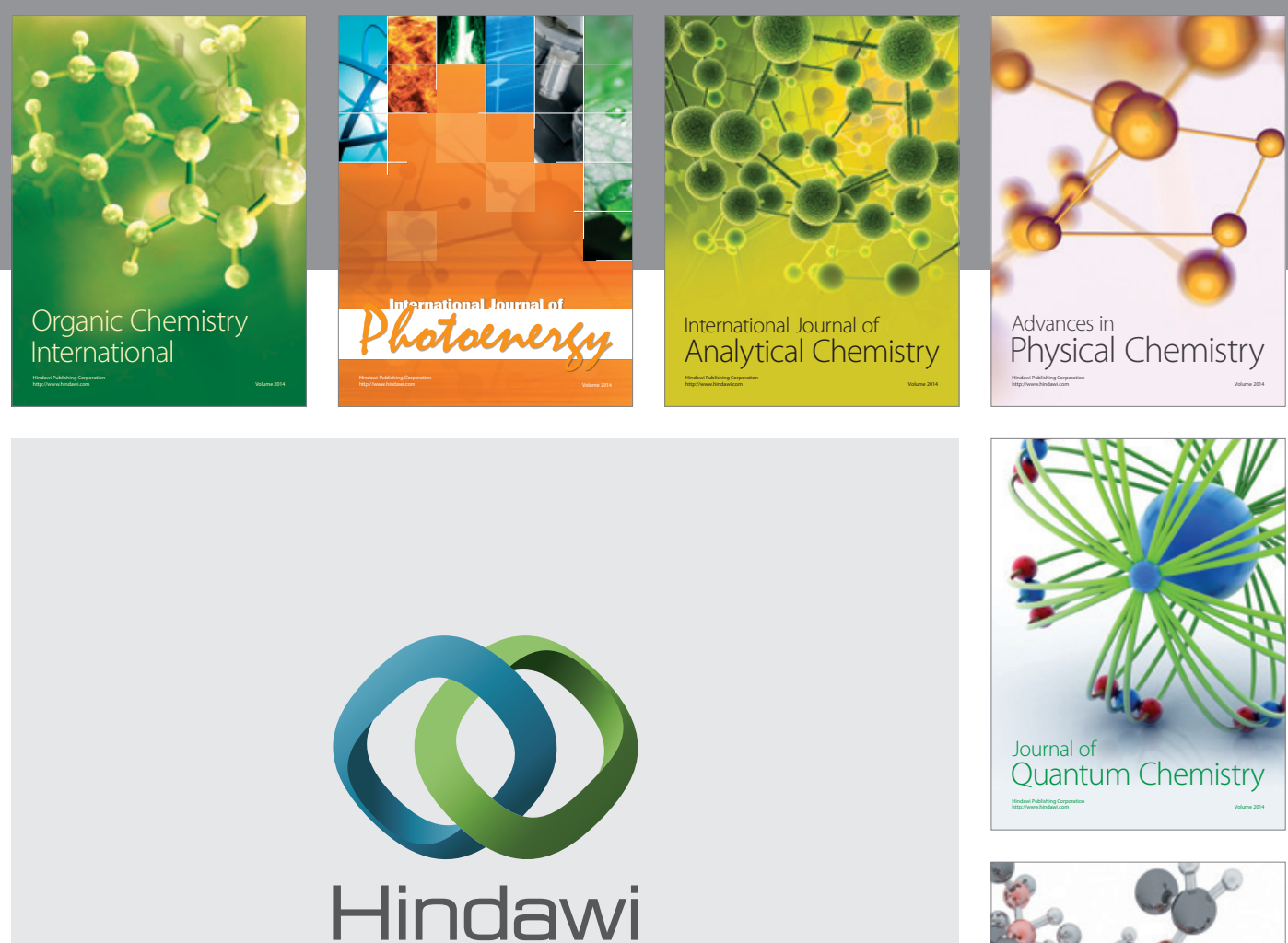

Submit your manuscripts at

http://www.hindawi.com

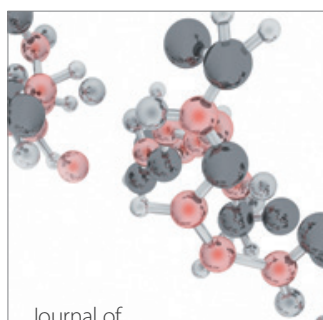

Analytical Methods

in Chemistry

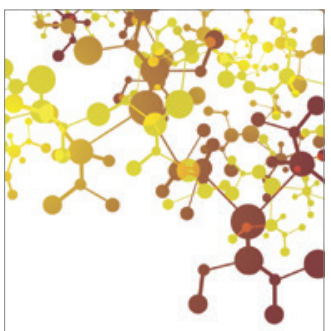

Journal of

Applied Chemistry

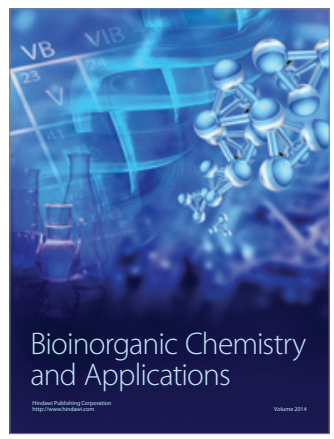

Inorganic Chemistry
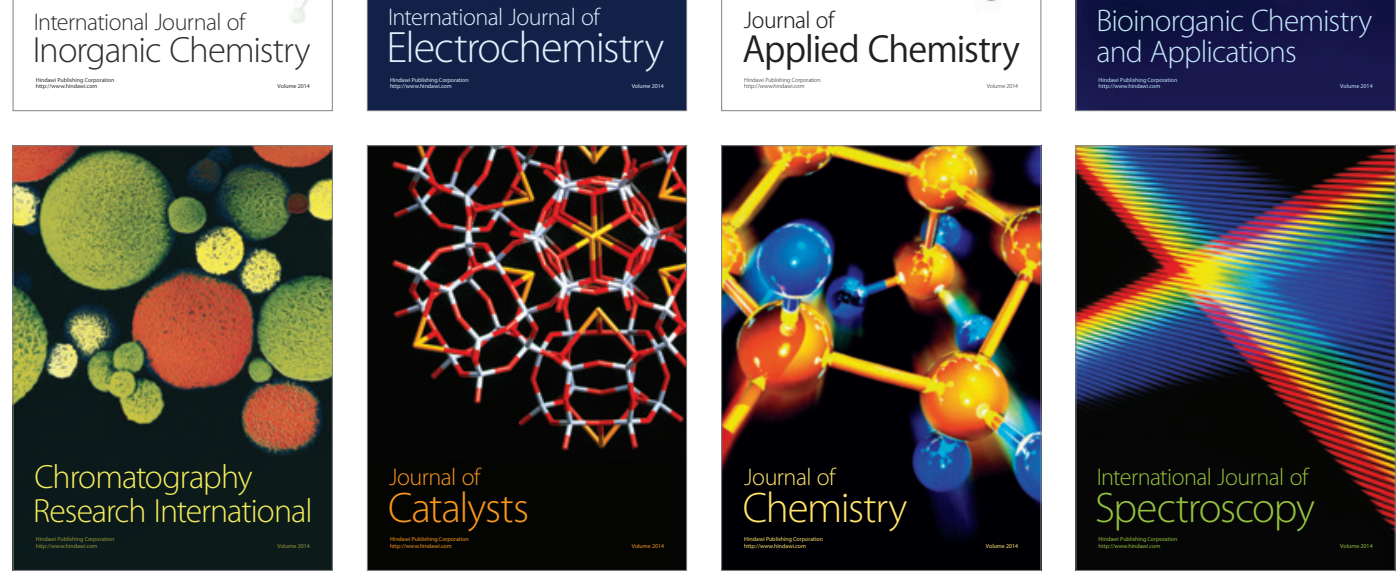